\title{
False-negative aldosterone-to-renin ratio in a primary aldosteronism patient complicated with primary polydipsia: case report
}

\author{
Chengcheng Zheng ${ }^{1}$, Lianling Zhao ${ }^{1}$, Chang Zheng ${ }^{2}$, Yan Ren ${ }^{1}$, Haoming Tian $^{1}$, Tao Chen ${ }^{1}$ \\ ${ }^{1}$ Department of Endocrinology and Metabolism, West China Hospital, Sichuan University, Chengdu, China; ${ }^{2}$ Department of Endocrinology, The \\ First People's Hospital of Guiyang, Guiyang, China \\ Correspondence to: Tao Chen. Department of Endocrinology and Metabolism, West China Hospital, Sichuan University, 37 Guoxue Street, Chengdu \\ 610041, China. Email: dr.chentao@qq.com.
}

\begin{abstract}
Aldosterone-to-renin ratio is the most reliable screening method of primary aldosteronism and has been widely used in clinical practice, but the index is influenced by many factors, some of which cause it false-negative, consequently leading to primary aldosteronism underdiagnosed. We report a rare case of a 27-year-old woman complaining of elevated arterial blood pressure and spontaneous hypokalemia but whose aldosterone-to-renin ratio were negative consecutively. She also had symptoms of polydipsia and polyuria for more than 20 years, with the volume of water intake and urine output up to 17 liters per day. Confirmatory tests of saline infusion test and captopril challenge test could not suppress plasma aldosterone concentration to the cutoff value. Abdominal contrast-enhanced CT suggested an adenoma on the right adrenal gland. After excluding other known causes of hypertension with hypokalemia, the patient was ultimately diagnosed with aldosterone-producing adenoma complicated with primary polydipsia. Complete clinical remission was achieved after unilateral adrenalectomy. The histopathology showed typical features of adrenocortical adenoma which was positive for CYP11B2 by immunohistochemistry, and next-generation sequencing results of tumor tissues revealed a missense mutation of the KCNF5 gene [chr11:128781619, c.451 (exon 2) $\mathrm{G}>\mathrm{A}]$. All these findings supported the diagnosis of aldosterone-producing adenoma. This study has shown that negative aldosterone-to-renin ratio screening result cannot simply exclude primary aldosteronism. Comprehensive patient's evaluation should be taken to avoid missed diagnosis in clinical work, especially for those who have potentially curative surgery.
\end{abstract}

Keywords: Primary aldosteronism; primary polydipsia; aldosterone-to-renin ratio; case report

Submitted Sep 01, 2021. Accepted for publication Dec 15, 2021.

doi: $10.21037 /$ gs-21-607

View this article at: https://dx.doi.org/10.21037/gs-21-607

\section{Introduction}

Primary aldosteronism (PA) is the most common cause of secondary hypertension, accounting for approximately $5-10 \%$ of patients with arterial hypertension (1), with an incidence of approximately $17-23 \%$ among refractory hypertensive patients (2). According to the published Endocrine Society clinical guidelines and consensus statements, aldosterone-to-renin ratio (ARR) is recommended for PA screening, which patients with positive ARR would be selected to undergo further confirmatory tests. ARR screening test increases the detection rate of PA among hypertensive patients by ten times (3). In present study, we reported a PA patient with false-negative ARR results, which were most likely caused by primary polydipsia (PP). Her hypokalemia and hypertension were completely relieved after unilateral adrenalectomy, and the results of pathology, immunohistochemistry and genetics of tumor tissues supported the diagnosis of aldosterone-producing adenoma (APA).

We present the following case in accordance with 

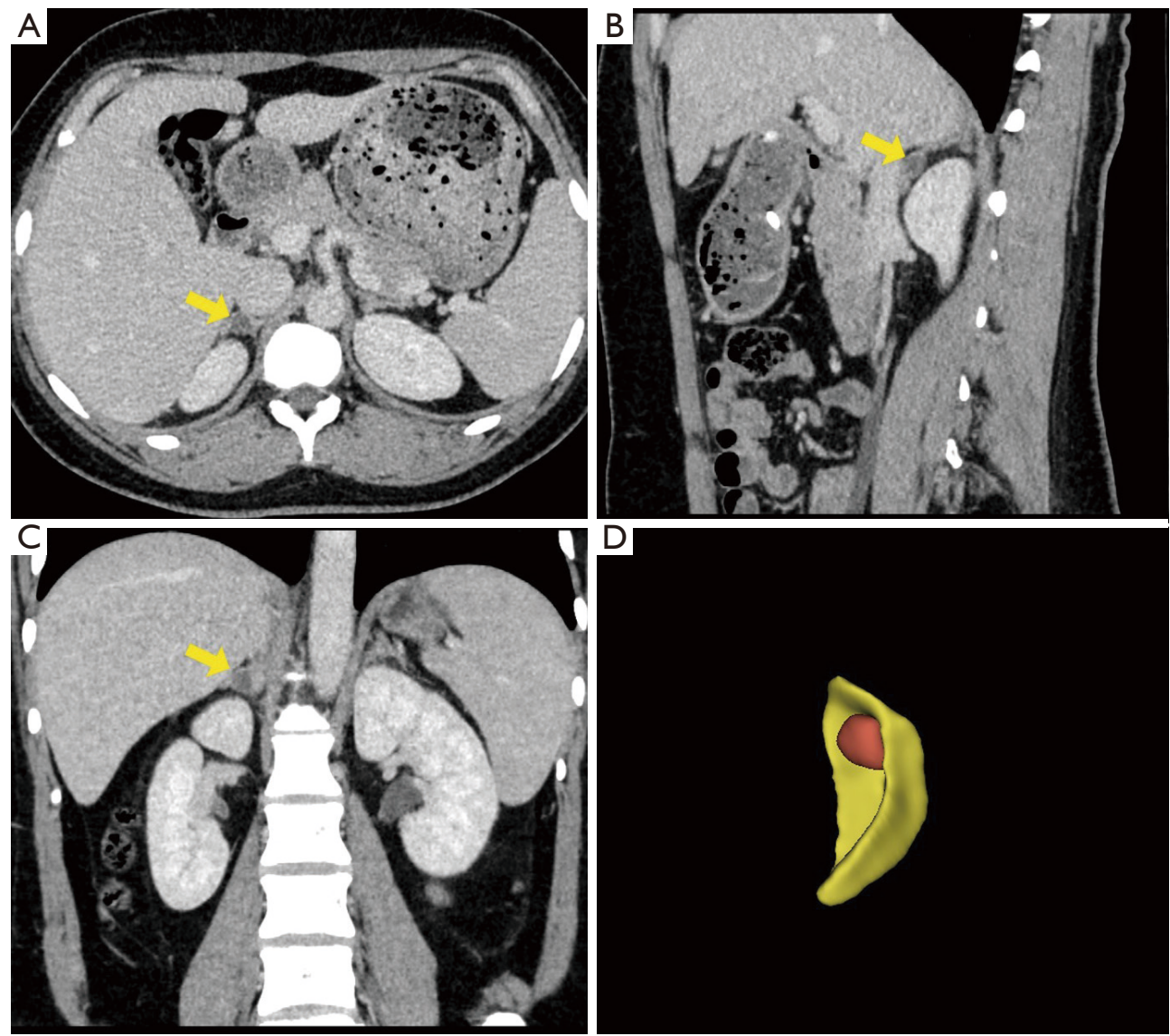

Figure 1 Adrenal glands in enhanced computed tomography scan. (A) Horizontal position; (B) sagittal position; (C) coronal position. The yellow arrow indicates an adenoma on the right adrenal gland; (D) 3D reconstructed image of right Adrenal gland and an adrenal adenoma drawn by 3D Slicer (Brigham and Women's Hospital, version 4.11, Harvard University, Boston, MA, USA).

the CARE reporting checklist (available at https:// gs.amegroups.com/article/view/10.21037/gs-21-607/rc).

\section{Case presentation}

A 27-year-old woman was admitted to our hospital complaining of elevated arterial blood pressure (BP) for more than one year. The highest $\mathrm{BP}$ measurement was $180 / 120 \mathrm{mmHg}$ and her BP fluctuated around 140/100 $\mathrm{mmHg}$ after receiving nifedipine and irbesartan. Four months ago, the laboratory examinations in her local hospital revealed serum potassium of $2.88 \mathrm{mmol} / \mathrm{L}$, plasm aldosterone concentration (PAC) of $20.20 \mathrm{ng} / \mathrm{dL}$ (reference value, 3.00-35.00 $\mathrm{ng} / \mathrm{dL}$ ), direct renin concentration (DRC) of $31.76 \mathrm{mU} / \mathrm{L}$ (reference value, 2.80-39.90 mU/L) and ARR of 0.64. Abdominal contrastenhanced CT suggested an adenoma on the right adrenal gland $(1.25 \times 0.78 \mathrm{~cm})$ (Figure 1). In our hospital, screening test was performed again after hypokalemia correction and anti-hypertension agent changes (terazosin and verapamil sustained-release tablets), but ARR was still negative (Table 1). Confirmatory tests of saline infusion test and captopril challenge test were further carried out considering the high possibility of PA, and aldosterone levels were both not suppressed to the cutoff value. Other laboratory examinations were normal such as routine blood tests, routine urinary tests, liver and kidney function, thyroid function, serum calcium, PTH, midnight serum cortisol, 24-hour urinary free cortisol, and catecholamine metabolites (NMNs). An ultrasonic cardiogram showed the left ventricle was slightly enlarged, and the interventricular septum was thickened, while ultrasonography of the aorta and bilateral renal arteries did not find lesions such as stenosis or dissection. 
Table 1 PA screening test results in supine and standing position in our hospital

\begin{tabular}{|c|c|c|c|c|c|c|}
\hline Variable & \multicolumn{2}{|c|}{ July 20, 2019} & \multicolumn{2}{|c|}{ July 23, 2019} & \multicolumn{2}{|c|}{ Follow-up with 6 months } \\
\hline $\mathrm{PRA}[\mathrm{ng} /(\mathrm{mL} \cdot \mathrm{h})]$ & 1.06 & 4.33 & 1.25 & 3.26 & 3.56 & 8.77 \\
\hline Reference & $0.05-0.79$ & $0.93-6.56$ & $0.05-0.79$ & $0.93-6.56$ & $0.05-0.79$ & $0.93-6.56$ \\
\hline PAC (ng/dL) & 24.76 & 27.15 & 21.52 & 17.47 & 22 & 31.06 \\
\hline ARR $[(\mathrm{ng} / \mathrm{dL}) /(\mathrm{ng} / \mathrm{mL} \cdot \mathrm{h})]$ & 23.36 & 6.27 & 17.22 & 5.36 & 6.18 & 3.54 \\
\hline
\end{tabular}

PRA, plasma renin activity; PAC, plasm aldosterone concentration; ARR, aldosterone-to-renin ratio.

Notably, the patient had symptoms of polydipsia and polyuria for more than 20 years. The volume of water intake and urine output were approximately 17 liters per day in the past 3 months. The water deprivation test was performed suggesting the possibility of $\mathrm{PP}$ or partial central diabetes insipidus (DI). Polydipsia and polyuria were not relieved after diagnostic treatment with oral desmopressin tablets (0.1 mg per day) for one month, thus PP was diagnosed.

Her parents both had hypertension history for many years. Her father had hypokalemic periodic paralysis, while her mother's serum potassium was normal. In addition, her mother had a history of polydipsia and polyuria and was cured after delivery. Next-generation sequencing (NGS) was tested in their peripheral blood samples and no known pathogenic gene mutations for Liddle syndrome, congenital adrenal hyperplasia, Gordon syndrome, Geller syndrome, apparent mineralocorticoid excess, Gitelman syndrome, Bartter syndrome, or hypokalemic periodic paralysis were detected (Joy Orient Translational Medicine Research Center Co., Ltd.).

Given the early-onset hypertension accompanied by spontaneous hypokalemia, a right adrenal nodule, and a normal contralateral adrenal gland and after excluding other known causes of hypertension with hypokalemia, the patient was clinically diagnosed with PA and highly suspected of APA in the right adrenal gland. With the consideration of patient's demand of being pregnant in the near future, and some studies reported that patients with PA are more likely to develop preeclampsia during pregnancy and have higher risks of cesarean section, premature infants, and low-birth-weight infants (4,5), laparoscopic right adrenalectomy was ultimately performed without undergoing adrenal venous sampling (AVS). Post-surgical pathology and immunohistochemical results of the tumor tissues were consistent with APA (Figure 2A-2C) (anti-
CYP11B1 antibody and anti-CYP11B2 antibody were purchased from Merck Millipore, Germany). NGS of the tumor tissues revealed a missense mutation of the KCN75 gene: chr11:128781619, c.451 (exon 2) G>A, which was reported as a pathogenic mutation for PA (6) (Figure 2D) (Joy Orient Translational Medicine Research Center Co., Ltd., China).

At a year and a half follow-up after surgery, the patient's serum potassium level returned to normal without any potassium supplementation, and her $\mathrm{BP}$ was well controlled around 110-130/70-90 $\mathrm{mmHg}$. During the time, she successfully became pregnant and delivered a healthy baby without any perinatal adverse events. All procedures performed in studies involving human participants were in accordance with the ethical standards of the institutional and/or national research committee(s) and with the Helsinki Declaration (as revised in 2013). Written informed consent was obtained from the patient for publication of this case report and accompanying images. A copy of the written consent is available for review by the editorial office of this journal.

\section{Discussion}

PA spontaneously secretes excessive aldosterone, which suppresses significantly renin secretion by reninangiotensin-aldosterone system (RAAS), leading to elevated ARR. However, it has been reported that approximately $27.5 \%$ of PA patients can present with normal or even elevated renin levels, which could influence diagnostic accuracy of ARR (7). Common factors causing ARR false negative include potassium status, sodium loading, pregnancy and antihypertensive drugs, some complicating diseases such as obstructive sleep apnea-hypopnea syndrome (OSAHS) and renal insufficiency (8-10). A 

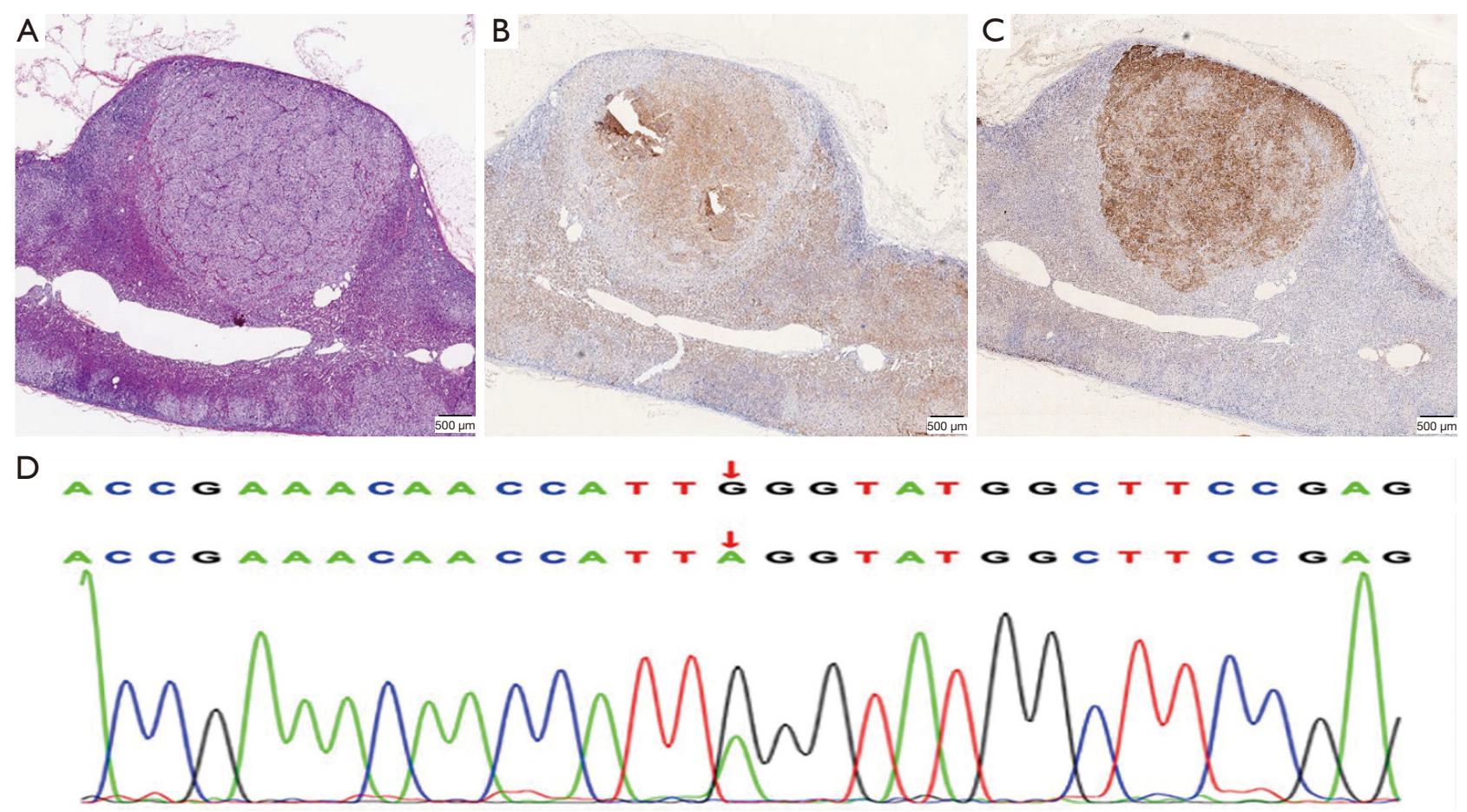

Figure 2 Immunohistochemistry of adrenal adenoma. (A) Hematoxylin \& eosin staining; (B) CYP11B1 immunohistochemistry; (C) CYP11B2 immunohistochemistry; (D) NGS of the tumor tissues find KCNF5 gene missense mutation (c.451G>A p.G151R).

potential explanation is that unlike the complete inhibition of adrenocorticotropin by a cortisol-producing adenoma, the inhibitory effect of PA on renin is relatively weak, and many factors such as ACTH and repeated orthostasis could weaken or even reverse renin suppression and exhibit negative ARR.

To the best of our knowledge, no previous studies have reported PA complicated with PP. PP is characterized by excessive fluid intake that leads to polyuria, with intact arginine vasopressin (AVP) secretion function and an appropriate antidiuretic renal response. Increased volume expansion caused by excessive fluid intake can suppress physiologically AVP (11). In many previous studies on the relationship between AVP and RAAS, it commonly argued that AVP can inhibit renin release, though precise mechanism remains unestablished. Several studies reported that AVP suppressed renin release significantly after stimulation by isoproterenol in the isolated perfused rat kidney or intact rats (12-14), So it might be assumed that AVP interferes with the mechanisms by which isoproterenol increases renin release (12). Another hypothesis is AVP can act as a neurotransmitter to inhibit the sympathetic nervous system. AVP-deficient mice tend to have increased sympathetic activity and higher renin secretion (15). Stimulated RAS activity was also proved as a compensatory mechanism by observing angiotensin I-converting enzyme inhibitor led to urine flow increased in DI rats (16). Besides, some studies claimed that due to AVP promote reabsorption of sodium on renal tubular, prolonged AVP decrease may cause sodium depletion which is known as stimulator of renin secretion $(17,18)$.

Taken together, false-negative ARR in the present case only reflected a single spot plasma renin and aldosterone levels but cannot reflect the status of excessive autonomous aldosterone production. The precise mechanism of PP causing ARR being false-negative in PA remains to be elucidated.

\section{Conclusions}

The study shows that PP can lead to false-negative ARR result in PA, it contributes to our further understanding of PA screening test, which is important but not absolutely necessary for PA diagnosis. A limitation of this study is the absence of AVS result due to patient's willingness of being pregnant in the near future. Overall, this study strengthens 
the idea that comprehensive evaluation of clinical manifestations and laboratory and imaging examinations is crucial for making a proper judgement in our clinical workup.

\section{Acknowledgments}

Funding: The cost of purchasing anti-CYP11B1 antibody and anti-CYP11B2 antibody was supported by the 1.3 .5 project for disciplines of excellence, West China Hospital, Sichuan University (grant number ZYGD18022).

\section{Footnote}

Reporting Checklist: The authors have completed the CARE reporting checklist. Available at https://gs.amegroups.com/ article/view/10.21037/gs-21-607/rc

Peer Review File: Available at https://gs.amegroups.com/ article/view/10.21037/gs-21-607/prf

Conflicts of Interest: All authors have completed the ICMJE uniform disclosure form (available at https://gs.amegroups. com/article/view/10.21037/gs-21-607/coif). The authors have no conflicts of interest to declare except the funding.

Ethical Statement: The authors are accountable for all aspects of the work in ensuring that questions related to the accuracy or integrity of any part of the work are appropriately investigated and resolved. All procedures performed in studies involving human participants were in accordance with the ethical standards of the institutional and/or national research committee(s) and with the Helsinki Declaration (as revised in 2013). Written informed consent was obtained from the patient for publication of this case report and accompanying images. A copy of the written consent is available for review by the editorial office of this journal.

Open Access Statement: This is an Open Access article distributed in accordance with the Creative Commons Attribution-NonCommercial-NoDerivs 4.0 International License (CC BY-NC-ND 4.0), which permits the noncommercial replication and distribution of the article with the strict proviso that no changes or edits are made and the original work is properly cited (including links to both the formal publication through the relevant DOI and the license). See: https://creativecommons.org/licenses/by-nc-nd/4.0/.

\section{References}

1. Mulatero P, Monticone S, Deinum J, et al. Genetics, prevalence, screening and confirmation of primary aldosteronism: a position statement and consensus of the Working Group on Endocrine Hypertension of The European Society of Hypertension. J Hypertens 2020;38:1919-28.

2. Calhoun DA. Is there an unrecognized epidemic of primary aldosteronism? Pro. Hypertension 2007;50:44753; discussion 447-53.

3. Gordon RD, Stowasser M, Tunny TJ, et al. High incidence of primary aldosteronism in 199 patients referred with hypertension. Clin Exp Pharmacol Physiol 1994;21:315-8.

4. Blumenfeld YJ. Evidenced-based care of pregnant women with symptomatic adrenal masses - accepting imperfect data. BJOG 2018;125:728.

5. Landau E, Amar L. Primary aldosteronism and pregnancy. Ann Endocrinol (Paris) 2016;77:148-60.

6. Mulatero P, Monticone S, Rainey WE, et al. Role of KCNJ5 in familial and sporadic primary aldosteronism. Nat Rev Endocrinol 2013;9:104-12.

7. Bravo EL, Tarazi RC, Dustan HP, et al. The changing clinical spectrum of primary aldosteronism. Am J Med 1983;74:641-51.

8. Funder JW, Carey RM, Mantero F, et al. The Management of Primary Aldosteronism: Case Detection, Diagnosis, and Treatment: An Endocrine Society Clinical Practice Guideline. J Clin Endocrinol Metab 2016;101:1889-916.

9. Ge Q, Li M, Zhang Y, et al. The Clinical Characteristics of Patients with Primary Aldosteronism Complicated with Obstructive Sleep Apnea - Hypopnea Syndrome. Journal of Hypertension 2017;35:E260.

10. Oelkers W, Diederich S, Bähr V. Primary hyperaldosteronism without suppressed renin due to secondary hypertensive kidney damage. J Clin Endocrinol Metab 2000;85:3266-70.

11. Sailer CO, Winzeler B, Nigro N, et al. Characteristics and outcomes of patients with profound hyponatraemia due to primary polydipsia. Clin Endocrinol (Oxf) 2017;87:492-9.

12. Konrads A, Hofbauer KG, Werner U, et al. Effects of vasopressin and its deamino-D-arginine analogue on renin release in the isolated perfused rat kidney. Pflugers Arch 1978;377:81-5.

13. Meyer DK, Boll H, Lauterwein B, et al. Inhibition of isoprenaline-induced increase in plasma renin concentration by vasoconstrictors. Experientia 1975;31:1071-2. 
14. Vandongen R. Inhibition of renin secretion in the isolated rat kidney by antidiuretic hormone. Clin Sci Mol Med 1975;49:73-6.

15. Golin RM, Gotoh E, Keil LC, et al. Lack of effect of vasopressin replacement on renin hypersecretion in Brattleboro rats. Am J Physiol 1989;257:R1117-22.

16. Mann JF, Rascher W, Schömig A, et al. Inhibition of the renin-angiotensin-system in Brattleboro rats with hereditary hypothalamic diabetes insipidus. Klin

Cite this article as: Zheng C, Zhao L, Zheng C, Ren Y, Tian H, Chen T. False-negative aldosterone-to-renin ratio in a primary aldosteronism patient complicated with primary polydipsia: case report. Gland Surg 2022;11(1):279-284. doi: 10.21037/gs-21-607
Wochenschr 1978;56 Suppl 1:67-70.

17. Antaraki A, Rangou D, Chlouverakis C. The reninaldosterone axis in patients with diabetes insipidus. Clin Endocrinol (Oxf) 1994;40:505-10.

18. Schalekamp MA, Donker SC, Jansen-Goemans A, et al. Dissociation of renin and aldosterone during dehydration: studies in a case of diabetes insipidus and adipsia. J Clin Endocrinol Metab 1976;43:287-94. 